\title{
Determining the Effect of Maternal Omega-3 Supplementation during Lactation on Growth and Development of Infants
}

\author{
Nasrin Nazeri ', Saeid Ghavamzadeh ${ }^{r}$
}

Received 23 Dec, 2016, accepted for publication 8 Feb, 2017

\begin{abstract}
Background \& Aims: Development during childhood is vital for learning skills. Maternal omega-3fatty acids during pregnancy and lactation play important role in childhood development. The aim of this study is to determine omega-3 supplementation during lactation on the growth and development of infants.

Materials \& Methods: This is a double-blind randomized trial. A total of 70 lactating women and their infants 15 days after delivery were selected. They were randomly divided into intervention and placebo groups. The intervention group received 1 gram omega-3 capsules daily and placebo group paraffin capsules for 3 months. Development of infants was assessed by using ASQ and growth by measuring weight, length and head circumference.

Results: The main score of communication, fine motor and problem solving in the intervention group after 3 months supplementation of omega-3 fatty acids were higher in the intervention group than placebo. There were no differences in gross motor and social development between two groups.
\end{abstract}

Conclusion: In this study positive effect of omega-3 e on problem solving and social development were found. There were no differences in growth between two groups except head circumference.

KeyWords: omega-3 supplement, lactation, growth, development

Address: Nutrition Department, Uremia University of Medical Science, Uremia, Iran

Tel: +989141518929

Email: nasrin. nazeri11yahoo.com

\section{Introduction}

Growing is defined as increasing in body size in different parts of the body (1) while development is of complex and so enormous issue which can be influenced by children's environment $(1,2)$. The study of evolution carried out in five domains of physical development, motor skills (gross and fine), emotional, communication, cognitive and problem-solving (understanding speech and speech). Evaluation of dimensions of development in infancy ages is very important due to the fast pace of change in the first year after birth (1). The first years of a child's life, especially the first year of life is the most important period of developmental skills (3) because in addition to the high speed of development in this sensitive period, basic functions such as behavior, emotions and motivation would evolved $(3,4)$.

The importance of nutrition in child development for decades was taken into consideration when it was

\footnotetext{
${ }^{1}$ MS student of Nutrition, Uremia University of Medical Science

${ }^{2}$ PHD, Uremia University of Medical Science (Corresponding Author)
} 
found that breastfed infants had cognitive functions better than formula-fed subjects $(5,6)$. Not only breast milk is a major source of energy for infants, but also includes important materials such as hormones, enzymes and antibodies (7).

One of the most important long-term and short-term benefits of breastfeeding is the increase of infants' development (4, 9-10). Omega-3 fatty acids are long-chain that is obtained from plants and food $(11,12)$. Since they are types of essential fatty acids therefore they haven't made in the body and must come into the human body through diet (13).

Omega-3 fatty acids include EPA (eicosapentaenoic acid) and DHA (docosahexaenoic acid) which in the body is made by using Alpha-linolenic acid and exist in cell wall phospholipids $(8,14,15)$. Recent studies have shown that EPA and DHA act as a second messenger and cause the release of acetylcholine and noradrenaline, which are involved in learning and memory transmitters and during the development of life. Both fatty acids are essential for brain development $(14,16)$.

Development in early childhood and infant health affect learning and the person's behavior in future (17).

Adequate physical growth and development is one of the reliable criteria for evaluating of health status of children, especially in the first year of life (18).

More than 200 million children under 5 old-years in the developing countries don't finish their developmental potential (19). Most infants on a routine basis in Iran in terms of increasing height, weight and head circumference are controlled and evaluation of their evolution has been ignored (20, 21). Since the studies conducted so far reported conflicting results $(22,23)$ this study was to evaluate the effect of Omega-3 supplements during breastfeeding on the growth and development of infants.

\section{Materials and Method}

This study has a code of 4101394-1721 form Urmia University of Medical Sciences and code of ethics 180, 1394 ir.umsu.rec. This research has been registered on IRCT with IRCT2015100313678N6 code. This study is double blind, randomized and placebo-controlled trial. A total of 70 breastfeeding women with their infants 15 days after delivery were selected among 249 breastfeeding women who referred to Ardabil Health Centers where they had mothers and child care files.

In this study, sampling was conducted randomly after obtaining the necessary permissions from Urmia University of Medical Sciences. For sampling, Ardabil city was divided into six clusters and samples were selected among eligible individuals from each cluster. Inclusion criteria included breastfeeding women who exclusively breastfed, aged between 35-18 years old, without complications during pregnancy and delivery, birth weight above $2500 \mathrm{~g}$ and singleton-birth. The exclusion criteria included having less than 18 and over 35 years of age, complications during pregnancy and childbirth, chronic diseases, birth weight less than $2500 \mathrm{~g}$, preterm labor and having twins. Participants were randomly assigned to two groups after explaining the purpose of the implementation and procedure of the study. Written informed consent was taken. The intervention group received daily capsules containing $180 \mathrm{mg}$ of Omega-3 EPA and the placebo group received paraffin oil for 3 months.

Participants were referred to health centers once a month. In the first appointment, method of storage and supplement consumption was explained. Dietary intervention in 30 cases and 30 to placebo for the placebo group were delivered. To ensure supplementation, subjects were asked to deliver packets of supplements into the next visit. Out of 
70 participants, 62 completed the study. 8 participants because of using formula-feeding supplies were excluded. Of 8 withdrawals 3 were in the intervention group and 5 were in the placebo group. A total of 30 patients in the placebo group and 32 patients in the intervention group completed the study. Individual and clinical information such as age, type of delivery, mother's occupation, education, number of children, mother's BMI, maternal weight during pregnancy, maternal satisfaction, infant gender, birth weight at birth, Apgar score, history of supplementation with B vitamins was recorded in a questionnaire. Apgar is the standard method for evaluation of apparently healthy newborns immediately after birth (24). Apgar score is given based on five physiologic signs (heart rate, respiratory effort, irritability reflections, natural strain muscles and skin color) which each of them has two scores. An Apgar score above 7 indicates a normal delivery and infant (25). 24-hour recall was used to evaluate the diet of lactating mothers. Description for dietary recall completing of questionnaires were presented to participants orally. Food consumption was converted from raw-to-cook by using standard weights $(26,27)$. Nutritionist software was used to diet analysis and then nutritional data were analyzed statically.

Height, weight and head circumference of the first month after birth until 6 months on a monthly basis were measured to examine infant development. Measurement of weight in infants under 1 was done by weighing scales available in the health center monthly.

Measurement of infants' height was done by lying on their sides with the apparatus in the Health Center in the form of a box and plastic meters beside it. The child's head circumference was measured with a number of plastic meter. ASQ questionnaire was used to evaluate the Ages \& Stages Child Development.

Age's questionnaire and the first steps of the questionnaire are to evaluate the development of the child based on age, which is widely used worldwide to evaluate the development of children (28-30).

This questionnaire was translated in Iran by Sajedi and his colleagues in 2012 and its reliability and validity were evaluated for Iranian children and used in health centers for the development of children (31). The evaluation of development was investigated in 5 domains of communication, gross motor, fine motor, problem solving and social. Ages and Stages Questionnaires of infants are available from 4 months to 36 months to assess development in children. This questionnaire was filled by parents and in each area 6 questions were answered with with yes, sometimes and not yet and gained scores were zero, five and ten respectively. The highest score in each area was 60 (32). In this study, the evaluation of development was performed in 4 and 6 months after birth.

\section{Results}

This study was aimed to evaluate the effect of Omega-3 Supplements during breastfeeding on the growth and development of infants. The mean age of women participating in the study in the intervention group was 26.8 and in the placebo group was 26.9 $(p=0.91)$. No significant difference was observed between the two groups by examining mean of the mother's age, mother's BMI, overweight during pregnancy, birth weight and Apgar score at birth infants. Information on these variables is presented in Table 1. 
Table 1. Evaluation of variables birth weight, overweight during pregnancy, BMI, APGAR and mother's age between the two groups of intervention and placebo

\begin{tabular}{cccc}
\hline Variables & Intervention group $(\mathrm{n}=30)$ & Placebo group $(\mathrm{n}=32)$ & P value \\
\hline Mother's age & $26.8 \pm 4.6$ & $26.9 \pm 2.9$ & 0.91 \\
\hline Mother's BMI & $26.3 \pm 2.4$ & $25.3 \pm 2.3$ & 1.25 \\
Birth weight & $31625 \pm 376.31$ & $3112.3 \pm 277.69$ & 0.55 \\
Overweight during pregnancy & $13.4 \pm 2.31$ & $13.0 \pm 2.31$ & 0.42 \\
APGAR & $7.4 \pm 0.5$ & $7.5 \pm 0.5$ & 0.45 \\
\hline
\end{tabular}

In Table (1) APGAR is the standard method for evaluation of apparently healthy newborns at birth. BMI was measured after delivery.

The frequency distribution of qualitative variables of baby's gender, maternal education, and mode of delivery, maternal parity and satisfaction is presented in Table 2. Significant difference was not found in the frequency between the two groups by evaluation of the frequency of these variables between the two groups. The two groups were in a state of relative equilibrium with each other in terms of confounding. 24-hour dietary recall was used for nutrition analysis and then was evaluated by Nutritionist version 4 software and then analyzed statistically by SPSS.

Table 2. Frequency distribution of indices of infant's gender, mother's education, mode of delivery, parity and gestational satisfaction between the two groups

\begin{tabular}{|c|c|c|c|c|c|}
\hline & & Frequency & Placebo group & $\begin{array}{l}\text { Intervention } \\
\text { group }\end{array}$ & $P$ value \\
\hline \multirow[t]{2}{*}{ Infant's gender } & Boy & 33 & 16 & 17 & 0.59 \\
\hline & Girl & 29 & 14 & 15 & \\
\hline \multirow[t]{2}{*}{ Mother's education } & Diploma and less & 43 & 20 & 23 & 0.43 \\
\hline & Academic & 19 & 10 & 9 & \\
\hline \multirow[t]{2}{*}{ Mode of delivery } & Vaginal Delivery & 38 & 21 & 17 & 0.13 \\
\hline & Cesarean & 24 & 9 & 15 & \\
\hline \multirow[t]{2}{*}{ Parity } & Primiparous & 25 & 12 & 13 & 0.58 \\
\hline & Multipara & 37 & 18 & 19 & \\
\hline \multirow[t]{2}{*}{ Gestational satisfaction } & Yes & 34 & 17 & 17 & 0.49 \\
\hline & No & 28 & 13 & 15 & \\
\hline
\end{tabular}

According to the above findings, significant improvement in the development in the domain of communication and gross motor and problem solving in the intervention group was found after 3 months of supplementation with omega-3 fatty acids compared to the placebo group. Fine motor and social development in the two domains were not significantly different between the two groups. 
Table 3.Comparison of developmental domains between the two groups after the intervention

\begin{tabular}{cccc}
\hline Variables & \multicolumn{2}{c}{ After intervention } & \multirow{2}{*}{ P value } \\
\cline { 2 - 4 } & Intervention group & Placebo group & \\
\hline Communication development & $55.64 \pm 1.68$ & $49.16 \pm 1.89$ & 0.05 \\
Gross motor & $50.46 \pm 1.95$ & $46.66 \pm 2.29$ & 0.03 \\
Fine motor & $50.31 \pm 1.76$ & $48.1 \pm 2.15$ & 0.82 \\
Problem solving & $53.28 \pm 2.72$ & $48.33 \pm 2.29$ & 0.02 \\
Social development & $55.78 \pm 2.23$ & $53.83 \pm 2.96$ & 0.51 \\
\hline
\end{tabular}

Table 3 shows the evaluation of infant development through the Ages and Stages Questionnaires which are available from 4 to 36 months.

Indices of weight, height and head circumference were used to examine infants' development monthly. Infants' development indicators were measured each month among participants who had referred to receive omega-3 and placebo.

Their mean had no significant difference among the groups before the intervention. After three months of intervention, the average weight in the intervention group was $1069.57 \pm 9689.06 \mathrm{~kg}$ and in placebo $731.54 \pm 9536.66 \mathrm{~kg}(\mathrm{p}=0.51)$. The average height in the intervention group was 2.071 \pm 64.62 and in the placebo group it was $1.51 \pm$ 64.13, $(\mathrm{p}=0.29)$ and the average head circumference in the intervention group was 1.081 \pm 44.48 in the placebo group it was $0.946 \pm 43.86$ $(\mathrm{p}=0.02)$.

According to the findings, differences between the groups in mean of head circumference are significant and there was no significant difference in height and weight between the two groups after intervention. There was no significant relationship between Apgar score and overweight during pregnancy, mother's BMI and the development of infants, infants' BMI and maternal occupational status.

Table 4. Comparison of growth measurements among infants before and after intervention among intervention and placebo groups

\begin{tabular}{|c|c|c|c|c|c|c|c|c|}
\hline \multirow[b]{2}{*}{ Variables } & \multicolumn{2}{|c|}{ Baseline } & \multicolumn{2}{|c|}{ Pre-intervention } & \multicolumn{2}{|c|}{ Post-intervention } & \multirow[b]{2}{*}{$\mathrm{p}$} & \multirow[b]{2}{*}{ p" } \\
\hline & $\begin{array}{l}\text { Intervention } \\
\text { group }(\mathrm{n}=32)\end{array}$ & $\begin{array}{l}\text { Placebo group } \\
\qquad(\mathrm{n}=30)\end{array}$ & $\begin{array}{c}\text { Intervention } \\
\text { group } \\
(\mathrm{n}=32) \\
\end{array}$ & $\begin{array}{l}\text { Placebo } \\
\text { group } \\
(\mathrm{n}=30)\end{array}$ & $\begin{array}{l}\text { Intervention } \\
\text { group }(n=32)\end{array}$ & $\begin{array}{l}\text { Placebo group } \\
\qquad(\mathrm{n}=30)\end{array}$ & & \\
\hline Height $(\mathrm{cm})$ & 50.38 & 73.49 & $53.29 \pm 1.7$ & $52.8 \pm 1.6$ & $64.62 \pm 2.1$ & $64.13 \pm 1.5$ & 0.34 & 0.29 \\
\hline $\begin{array}{l}\text { Weight(Gra } \\
\mathrm{m})\end{array}$ & $3162.5 \pm 376.31$ & $3112.3 \pm 277.69$ & $\begin{array}{c}4835.9 \pm 549 \\
3 \\
\end{array}$ & $4971.6 \pm 572.7$ & $\begin{array}{c}9689.06 \pm 1069.5 \\
7 \\
\end{array}$ & $9536.66 \pm 731.54$ & 0.34 & 0.51 \\
\hline $\begin{array}{c}\text { Head } \\
\text { circumferenc } \\
\text { e (cm) }\end{array}$ & $34.3 \pm 0.42$ & $34.2 \pm 0.29$ & $36.8 \pm 0.84$ & $36.6 \pm 0.99$ & $44.48 \pm 1.08$ & $43.86 \pm 0.49$ & 0.45 & 0.02 \\
\hline
\end{tabular}

$\mathrm{P}$ is for pre-intervention and $\mathrm{p} "$ is for post-intervention.

Standard error, t-test and $\mathrm{P}$ value for placebo and intervention groups before and after the intervention were presented in the table. 


\section{Discussion and Conclusion}

Since omega-3 fatty acids are essential components for central nervous system and the brain, it was received much more attention $(23,33)$. Omega-3 supplementation during pregnancy and breastfeeding can have fruitful results for children and mothers (9). Studies in this regard have shown conflicting results $(23,34)$. In this study, after 3 months of supplementation with omega-3, the average height and weight of infants did not show significant difference compared to placebo. But the increase in the average head circumference was seen in the intervention group that was not a statistically significant value. In terms of Omega-3 and its effect on infant growth, the obtained results of this study were consistent with the results of Saccone (35); however, they examined the effect of omega-3 supplementation during pregnancy. The results of this study are consistent with results of Decsi and colleagues (36), but they did not report any difference in growth between groups after supplementation with omega-3 compared to infants fed formula and breast milk.

Much et al. reported that the positive relationship between consumption of omega-3 and height at birth (37) which is inconsistent with our results. They reported that omega-3 supplementation increases head circumference and weight of the newborns with low birth weight. It is likely that this discrepancy is due to the compensation mechanism in babies with low birth weight. It appears that studies with different designs reported different results. Thus the need for further clinical trials with different doses and duration of the effect of omega3 on infant growth and development is essential.

In this study, after 3 months of supplementation of omega-3 during early lactation it was observed positive effects on the development of infants. The results obtained from this study in the domain of the development of infants are similar to the findings of Dunstan et al in 2007 where they reported DHA and EPA content of breast milk had a positive relationship with Griffith Developmental Test (38). On the other hand Hurtado in 2015 reported that omega-3 supplementation during pregnancy and lactation, maternal and child affects the lipid profile, but no effect on cognitive and visual development (39). In the year 2011, Campoy et al. did not find a significant effect of omega-3 supplementation during pregnancy on children's development, however, they emphasized that the omega- 3 content of the mother may be associated with cognitive performance in children' later life (40). These results differ from the findings of this study. While the relationship between problems and brain development with omega-3 levels have been confirmed in many researches and reported that it decreases levels of omega-3 in the wall of erythrocytes in patients with central nervous system disorders (41) (34). Most studies have been performed during pregnancy and only a limited number included breastfeeding and pregnancy so the separation of the effects of omega- 3 during this period was one of the problems and limitations of the studies. Most studies were done with small size (26-30-32-42-51) participants and in some cases missing cases especially in the intervention group were high.

It seems more samples are needed to diagnose its effects for determining the effect of omega-3 on the development. Studies should be performed in large samples of low-income populations that are at risk of brain problems, developmental delay with doseresponse assessment (15).

Evolution and existing tests may not be sensitive enough, in addition, the combination of several different neurological tests can increase potential biological mechanisms involved in certain foods 
increase (15). The combination of new techniques and electrophysiological responses as the gold standard methodology should be considered in the objectives of the effects of nutrition in brain development (40). According to the different obtained results from different studies, it seems that an optimal level of DHA and EPA for the evaluation of development should be exist.. Only a few studies have been performed on lactation and breastfeeding, which plays an important role in the development of infants require more attention. Because of the importance of omega-3 fatty acids for breastfeeding women and their infants and the limited number of studies, further studies are needed to estimate optimal omega-3 intake in lactating women and infants $(42,43)$.

\section{Limitations}

One limitation of this study was the small sample size. Evaluation of several variables in the small sample size is not a good choice and should be done in a larger number of samples, but due to financial constraints it was not possible.

Another limitation of the study was collecting information such as birth weight, birth length and head circumference and Apgar from records of pregnant women and families. Since, the information used in this study was reported by operators helped a baby be delivered and before the start of the study, the accuracy of measurement is hidden to us.

\section{Recommendations}

Due to the desired effect of omega-3 supplementation during breastfeeding on the development of infants, its consumption is recommended during breastfeeding by nursing mothers. Given that supplementation with omega-3 caused a slight increase in head circumference of infants and the importance of infant growth during the first years of life, especially in preterm infants, it seems that clinical trial studies with different doses of omega3 is required to review the beneficial effect on infant growth in particular, growth retardation and preterm infants.

\section{Acknowledgements}

The authors appreciated all women in this study and also greatly appreciate the cooperation and support of the authorities and staff of Ardabil Health Centers.

\section{References}

1. Solimani F, Karimi H. THe assesment high risk of delay development of infants. Tavanbakhshi 1384;6(1):9-10.

2. Ghahramani M TJ, Chamanzari H. The survey of developmental creteria of one year old infant in Gonabad city and its comparison to standard index. J Med Sci school Gonabad 2002;2(8):89-91. (Persian)

3. Nahar B, Hamadani JD, Ahmed T, Tofail F, Rahman A, Huda SN, et al. Effects of psychosocial stimulation on growth and development of severely malnourished children in a nutrition unit in Bangladesh. Eur J Clin Nutr 2009;63(6):725-31.

4. Jedrychowski W, Perera F, Jankowski J, Butscher M, Mroz E, Flak E, et al. Effect of exclusive breastfeeding on the development of children's cognitive function in the Krakow prospective birth cohort study. Eur J Pediatr 2012;171(1):151-8.

5. Davis K, Pearlstein T, Stuart S, O'Hara M, Zlotnick C. Analysis of brief screening tools for the detection of postpartum depression: comparisons of the PRAMS 6item instrument, PHQ-9, and structured interviews. Arch Womens Ment Health 2013;16(4):271-7.

6. Markhus MW, Skotheim S, Graff IE, Froyland L, Braarud HC, Stormark KM, et al. Low omega-3 index in pregnancy is a possible biological risk factor for postpartum depression. PloS one 2013;8(7):e67617. 
7. Steer CD, Lattka E, Koletzko B, Golding J, Hibbeln JR. Maternal fatty acids in pregnancy, FADS polymorphisms, and child intelligence quotient at $8 \mathrm{y}$ of age. Am J Clin Nutr 2013;98(6):1575-82.

8. Gustafsson PA, Duchen K, Birberg U, Karlsson T. Breastfeeding, very long polyunsaturated fatty acids (PUFA) and IQ at $61 / 2$ years of age. Acta paediatr 2004;93(10):1280-7.

9. Innis SM. Omega-3 Fatty acids and neural development to 2 years of age: do we know enough for dietary recommendations? J Pediatr Gastroenterol Nutr 2009;48 Suppl 1:S16-24.

10. Bahrami G, Masoumi M, Rahimi Z. Co-existence of fatty acids changes in aorta artery and adipose tissue; comparison between $\mathrm{CAD}$ and non $\mathrm{CAD}$ patients. $\mathrm{J}$ Thromb Thrombolysis 2009;27(2):185-90.

11. Waylen A, Ford T, Goodman R, Samara M, Wolke D. Can early intake of dietary omega-3 predict childhood externalizing behaviour? Acta paediatr 2009;98(11):1805-8.

12. Makrides M, Gibson RA, McPhee AJ, Yelland L, Quinlivan J, Ryan P, et al. Effect of DHA supplementation during pregnancy on maternal depression and neurodevelopment of young children: a randomized controlled trial. JAMA 2010;304(15):1675-83.

13. Dunstan JA, Roper J, Mitoulas L, Hartmann PE, Simmer K, Prescott SL. The effect of supplementation with fish oil during pregnancy on breast milk immunoglobulin A, soluble CD14, cytokine levels and fatty acid composition. Clinical and experimental allergy. $\mathrm{J} \quad \mathrm{Br}$ Soc Allergy Clin Immunol 2004;34(8):1237-42.

14. Fontani G, Corradeschi F, Felici A, Alfatti F, Migliorini S, Lodi L. Cognitive and physiological effects of Omega-3 polyunsaturated fatty acid supplementation in healthy subjects. Eur J Clin Invest 2005;35(11):691-9.
15. Campoy C, Escolano-Margarit MV, Anjos T, Szajewska H, Uauy R. Omega 3 fatty acids on child growth, visual acuity and neurodevelopment. Br J Nutr 2012;107 Suppl 2:S85-106.

16. Van Goor D-BJ, Muskit F and et al. Supplementation of DHA but not DHA with arrachidonic acid during pregnancy and lactation influences general movment qulity in 11 week old term infants. $\mathrm{Br} \mathrm{J}$ Nutr 2010;103(53):235-42.

17. Mustard J. Experience-based brain development: Scientific underpinnings of the importance of early child development in a global world. Paediatr Child Health 2006;11(9):571-2.

18. SafariM. The assessment growgth and development and related factors of 2 years old children in yasoj. $\mathbf{J}$ Shahid Beheshty Univ 2009 ; 67(19): 353-58. (Persian)

19. Kerstjens JM, Bos AF, Ten Vergert EM, de Meer G, Butcher PR, Reijneveld SA. Support for the global feasibility of the Ages and Stages Questionnaire as developmental screener. Early hum develop 2009;85(7):443-7.

20. Solimani F, Khoshbin A. Report of physical delay screening of infants (4-18 mounth) in Karaj. Tavanbakhshi 2009; 7(6): 1-7 . (Persian)

21. KosarianM, Vahid shahi K. Delay disorder screening of children in Sary. J Mazandaran Univ 2006:17(9):6975. (Persian)

22. Murray L, Woolgar M, Murray J, Cooper P. Selfexclusion from health care in women at high risk for postpartum depression. J Public health Med 2003;25(2):131-7.

23. Mozurkewich EL, Klemens C. Omega-3 fatty acids and pregnancy: current implications for practice. Curr Opin Obstet Gynecol 2012;24(2):72-7.

24. Jepson HA, Talashek ML, Tichy AM. The Apgar score: evolution, limitations, and scoring guidelines. Birth 1991;18(2):83-92. 
25. Apgar V. A Proposal for a New Method of Evaluation of the Newborn Infant. Originally published in July 1953, volume 32, pages 250-259. Anesth Analg 2015;120(5):1056-9.

26. Mermira P. Doctrine of diet set up. Specific Deseasies Center. 2000:9(2):88-909. (Persian)

27. kianfar H, Hoshyar A. Convert of food into house measuring. Tehran: Agriculture Sceince of Tehran; 1999. (Persian)

28. Wendy H Oddy RM, Kendal GE, Zubrik SR, Stanley FJ. Breastfeeding and early child development : a prospective cohort study fundation Acta Pardiat 2011;100:992-9.

29. Armijo I, Schonhaut L, Cordero M. Validation of the Chilean version of the Ages and Stages Questionnaire (ASQ-CL) in Community Health Settings. Early Hum Dev 2015;91(12):671-6.

30. Eun Young KM, Kyung Sung MD, . The ages and Stages Questionnaire : A Screening for developmental delay in the setting of a pediatric clinic. Korean $J$ Pediat 2007;11(5):50-5.

31. sajedi F, Vamegi R, Delavar B. Validity of ASQ screening for Iranian children. J Tehran Univ 2005:436-46. (Persian)

32. Halbwachs M, Muller J-B, Nguyen The Tich S, de La Rochebrochard E, Gascoin G, Branger B, et al. Usefulness of parent-completed ASQ for neurodevelopmental screening of preterm children at five years of age. PLoS ONE 2013;8(8):e71925.

33. Mozurkewich E, Chilimigras J, Klemens C, Keeton K, Allbaugh L, Hamilton S, et al. The mothers, Omega-3 and mental health study. BMC Pregnancy Childbirth 2011;11:46.

34. Gould JF, Smithers LG, Makrides M. The effect of maternal omega-3 (n-3) LCPUFA supplementation during pregnancy on early childhood cognitive and visual development: a systematic review and metaanalysis of randomized controlled trials. Am J Clin Nutr 2013;97(3):531-44.
35. Saccone G, Berghella V, Maruotti GM, Sarno L, Martinelli P. Omega-3 supplementation during pregnancy to prevent recurrent intrauterine growth restriction: systematic review and meta-analysis of randomized controlled trials. Ultrasound Obstet Gynecol 2015;46(6):659-64.

36. Decsi T, Koletzko B. Growth, fatty acid composition of plasma lipid classes, and plasma retinol and alphatocopherol concentrations in full-term infants fed formula enriched with omega- 6 and omega-3 longchain polyunsaturated fatty acids. Acta Paediat 1995;84(7):725-32.

37. Much D, Brunner S, Vollhardt C, Schmid D, Sedlmeier EM, Bruderl M, et al. Effect of dietary intervention to reduce the $n-6 / n-3$ fatty acid ratio on maternal and fetal fatty acid profile and its relation to offspring growth and body composition at 1 year of age. Eur J Clin Nutr 2013;67(3):282-8.

38. Dunstan JA, Mitoulas LR, Dixon G, Doherty DA, Hartmann PE, Simmer K, et al. The effects of fish oil supplementation in pregnancy on breast milk fatty acid composition over the course of lactation: a randomized controlled trial. Pediat Res 2007;62(6):689-94.

39. Hurtado JA, Iznaola C, Pena M, Ruiz J, Pena-Quintana L, Kajarabille N, et al. Effects of Maternal Omega-3 Supplementation on Fatty Acids and on Visual and Cognitive Development. J Pediatr Gastroenterol Nutr 2015;61(4):472-80.

40. Campoy C, Escolano-Margarit MV, Ramos R, Parrilla-Roure M, Csabi G, Beyer J, et al. Effects of prenatal fish-oil and 5-methyltetrahydrofolate supplementation on cognitive development of children at $6.5 \mathrm{y}$ of age. Am J Clin Nutr 2011;94(6 Suppl):1880S-8S.

41. Assisi A, Banzi R, Buonocore C, Capasso F, Di Muzio $\mathrm{V}$, Michelacci F, et al. Fish oil and mental health: the role of n-3 long-chain polyunsaturated fatty acids in cognitive development and neurological disorders. Int Clin Psychopharmacol 2006;21(6):319-36. 
42. Jensen CL, Lapillonne A. Docosahexaenoic acid and lactation. Prostaglandins Leukot Essent Fatty Acids 2009;81(2-3):175-8.
43. Carlson SE, Salem N. Essentiality of omega 3 fatty acids in growth and development of infants. World Rev Nutr Diet 1991;66:74-86. 